OPEN ACCESS

Edited by:

Liang Wu,

Chongqing University, China

Reviewed by:

You Zhang

Beijing Institute of Petrochemical

Technology, China

Zhihui Xie,

China West Normal University, China

*Correspondence:

Jingying $B a$

baijy1213@163.com

Specialty section:

This article was submitted to

Structural Materials,

a section of the journal

Frontiers in Materials

Received: 31 May 2021

Accepted: 27 August 2021

Published: 18 November 2021

Citation:

Wen C, Bai J, Zhao K, Cui Q, Jiao B, Wang $X$ and Zhang $L$ (2021) Corrosion Initiation Behavior of Thermal Control

Oxidation Film of LA103Z Alloy.

Front. Mater. 8:717663.

doi: $10.3389 /$ fmats.2021.717663

\section{Corrosion Initiation Behavior of Thermal Control Oxidation Film of LA103Z Alloy}

\author{
Chen Wen, Jingying Bai ${ }^{*}$ Kuo Zhao, Qingxin Cui, Baocheng Jiao, Xuguang Wang and \\ Ligong Zhang
}

Beijing Spacecrafts, China Academy of Space Technology, Beijing, China

The magnesium lithium thermal control oxidation is a commonly used conductive anticorrosion treatment method for aerospace. The corrosion behaviors of thermal control oxidation films for LA103Z alloys were studied in 3.5\% NaCl solution. The corrosion characteristics with different immersion time were characterized by using scanning electron microscopy, energy spectroscopy, and electrochemical methods. The results showed that the corrosion of Mg-Li alloy with chemical oxidation film starts from pitting corrosion, gradually expands in depth in the early stage, forms corrosion holes, and then gradually develops into river-like morphology. In the last stage, the increasing corrosion products slow down the corrosion rate and gradually covers the entire sample surface. The corrosion product mainly consists of $\mathrm{MgO}, \mathrm{LiF}$, and $\mathrm{MgCl}_{2}$. Combined with the electrochemical characteristics, the corrosion mechanism was investigated.

Keywords: corrosion, LA103Z, thermal control coating, electrochemical, electrochemical., initiation

\section{INTRODUCTION}

As the lightest metallic structural materials $\left(1.30-1.65 \mathrm{~g} / \mathrm{cm}^{3}\right), \mathrm{Mg}$ - $\mathrm{Li}$ alloys have been widely used in space fields (Wu et al., 2020a; Wu et al., 2020b). In order to satisfy the functional requirements and adapt to the space environment, it needs to take out surface treatment such as plating, oxidation, and coatings for Mg-Li alloys (Xia et al., 2019; Zhang et al., 2019; Liu et al., 2021). However, due to the electrochemical activity of $\mathrm{Mg}$ and $\mathrm{Li}$, the alloys have great corrosion risks in the service environment (Prando et al., 2019; Sun et al., 2020). Although there are few corrosive factors in space, the coastal launch site can bring severe corrosion for the products. Oxidation methods can form thermal control coatings, anti-corrosion coatings, coating suitable for bonding, etc., which are suitable for the structure applications of satellites (Shi et al., 2015; Guo et al., 2017; Yang et al., 2018; Qiu et al., 2020).

In order to improve cementing property, it is needed to reduce thickness of the coating; however, the thin coating is useless for preventing corrosion. Many researchers have made efforts to form thin coating with good corrosion resistance (Wang et al., 2007; Chen et al., 2011; Formosa et al., 2012; Fernández et al., 2019). Fernandez et al. (Fernández et al., 2019) found that reduced graphene oxide onto magnesium discs by electrochemical and chemical methods can decrease the corrosion rate. The results obtained by Chen et al. (Chen et al., 2011) indicated that all the conversion coating formed in different solutions exhibits amorphous structure. The formation of Mo on the surface of $\mathrm{Mg}$ alloys after chemical oxidation can significantly improve the corrosion resistance (Shao et al., 2017). Xu et al. (Xu et al., 2008) produced oxide film of $2-3 \mu \mathrm{m}$ by the environment friendly chemical oxidation method. The corrosion resistance rate of the film in $3 \% \mathrm{NaCl}$ solution was only $1 / 15$ of $\mathrm{Mg}$ alloy substrates. Wang et al. (Liu et al., 2016) used black chemical oxidation to form a film, which had uniform blackness and dense film. 
TABLE 1 | Chemical composition of LA103Z magnesium-lithium alloy (wt\%).

\begin{tabular}{lcccccc}
\hline Element & Li & Al & Zn & Si & Fe & Mg \\
\hline Content/\% & 10.0 & 3.2 & 2.8 & 0.05 & 0.05 & Bal
\end{tabular}

In this paper, the thin film of magnesium lithium LA103Z was fabricated by chemical oxidation, and the corrosion behavior was studied by immersion test in $3.5 \mathrm{wt} \% \mathrm{NaCl}$ solution. The morphologies and corrosion products were characterized, combined with the electrochemical analysis of sample with different corrosion time, and the corrosion evolution mechanism was also studied.

\section{EXPERIMENTAL SECTION}

\section{Experimental Sample and Procedure}

The specimen used for the test is LA103Z magnesium lithium alloy, and the chemical composition is given in Table 1. The material was cut into $40 \mathrm{~mm} \times 40 \mathrm{~mm} \times 2 \mathrm{~mm}$ for experiment. Moreover, the specimens were polished by sandpaper from $400 \#$, $800 \#$, to $1,000 \#$.

Before oxidation, the specimens of LA103Z magnesium lithium alloy were degreased with absolute ethanol and then cleaned by deionized water $\rightarrow$ activation treatment by fluoride salt with concentration of $2.5 \mathrm{~g} / \mathrm{L} \rightarrow$ cleaned by deionized water $\rightarrow$ dried by compressed air. The chemical oxidation was carried out to obtain a thermal control film.

After oxidation, the specimens were sealed and protected by chloroprene rubber, except for an area of $40 \mathrm{~mm} \times 40 \mathrm{~mm}$ for the immersion test. The specimens were soaked in $3.5 \% \mathrm{NaCl}$ solution at the temperature $45^{\circ} \mathrm{C}$ with different times $(1,3,6$,
12, 18, 24h). After immersion with the assumed time, the specimens were cleaned by deionized water and dried by compressed air. Specimens with different immersion time were cut off by cross-section and observed by SEM.

\section{Characterization}

After immersion test, the morphologies of the specimens were characterized by metallurgical microscope (MO, Canon E60) and scanning electron microscope (SEM, SUPRA55VPX,Germany). The composition of corrosion products was characterized by $\mathrm{x}$-ray diffraction (XRD, Bruker AXS D8, Cu target, scan rate of $5^{\circ} /$ min, scan range of $10^{\circ}-90^{\circ}$ ).

The electrochemical evaluation with different immersion time was performed by using IM6 electrochemical equipment in $3.5 \mathrm{wt}$ $\% \mathrm{NaCl}$ solution at room temperature. The experiment employed a three-electrode system, a saturated calomel (SCE) electrode as reference electrode, a $\mathrm{Pt}$ electrode as counter electrode, the magnesium lithium alloy chemical oxidation sample as working electrode, and the sample exposure area was $1 \mathrm{~cm}^{2}$. The open circle potential (OCP) was tested for $600 \mathrm{~s}$. The electrochemical impedance spectroscopy (EIS) was tested with sinusoidal signal disturbance voltage amplitude of $10 \mathrm{mV}$. The frequency range is $100 \mathrm{kHz}-10 \mathrm{mHz}$. The polarization curve test range is $-0.5 \mathrm{~V} \sim+0.5 \mathrm{~V}$ ( $v s \mathrm{OCP}$ ), scan rate is $5 \mathrm{mV} / \mathrm{s}$, the range of cyclic voltammetry test voltage is $-0.25 \mathrm{~V} \sim+0.25 \mathrm{~V}$ (vs OCP), and the scan rate is $5 \mathrm{mV} / \mathrm{s}$.

\section{RESULTS AND DISCUSSION}

\section{Corrosion Morphologies}

The morphology of the film and its element content are shown in Figure 1. The surface of the film contains many micro cracks and holes. The main elements are $\mathrm{Mg}, \mathrm{O}$, and $\mathrm{Cr}$.
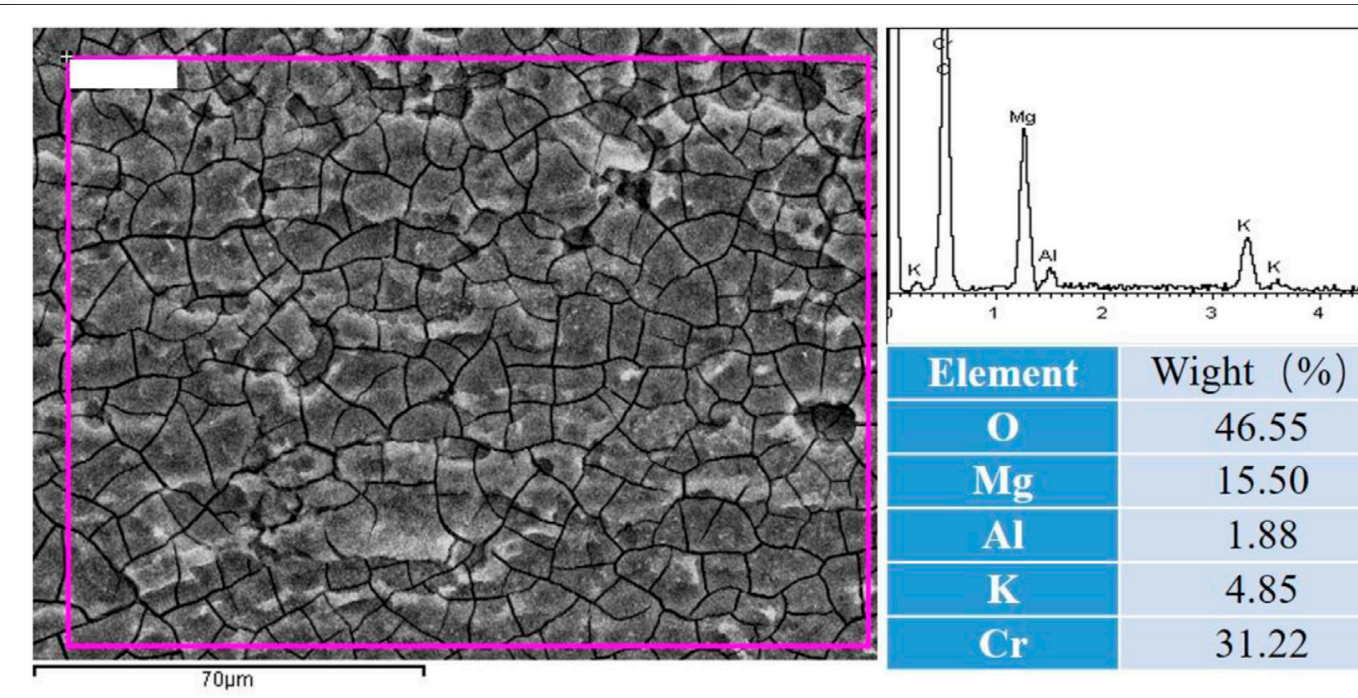

Wight (\%)
46.55
15.50
1.88
4.85
31.22

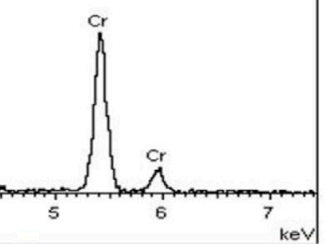

FIGURE 1 | The morphology and element content of the film. 

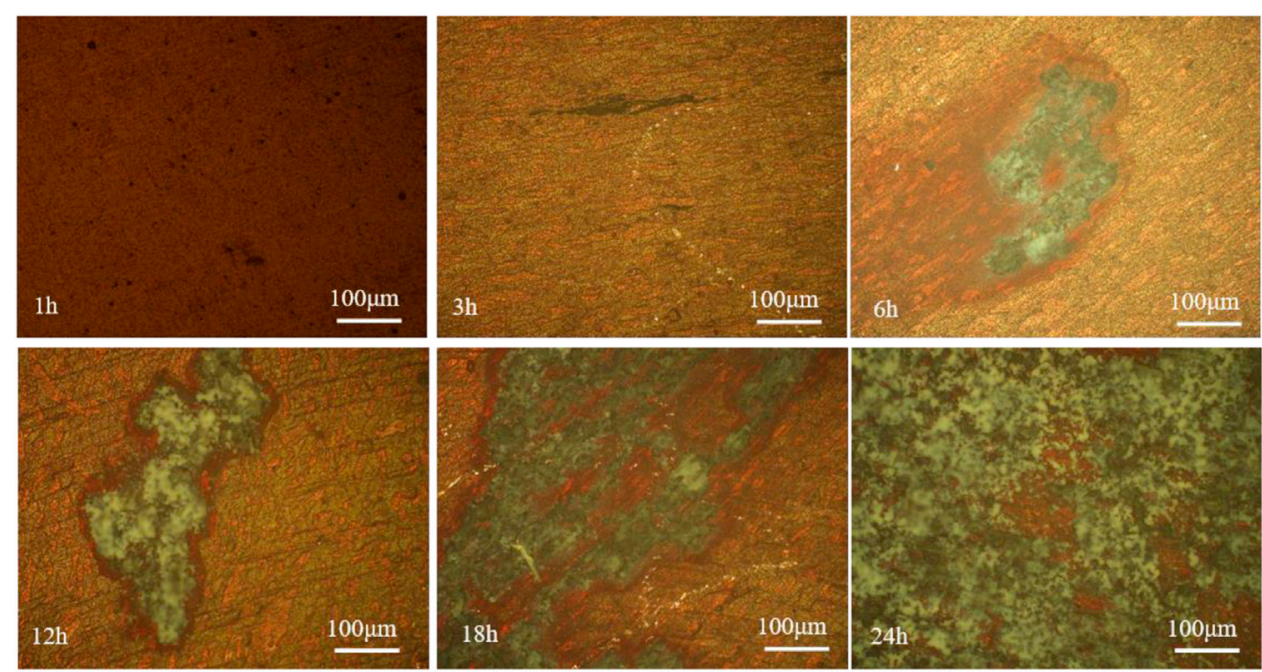

FIGURE 2 | Surface morphologies of the specimens in $3.5 \% \mathrm{NaCl}$ solution.

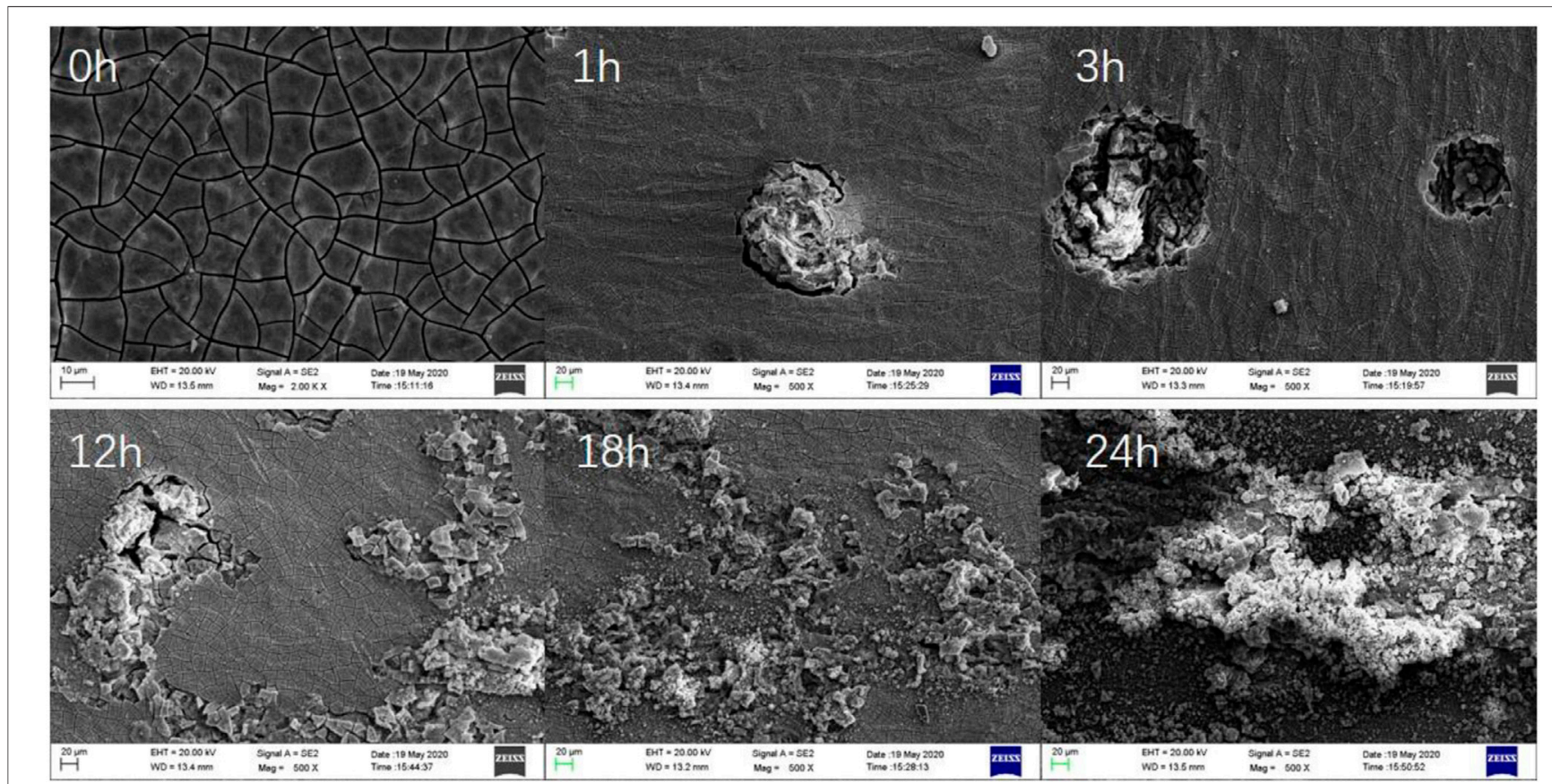

FIGURE 3 | SEM morphologies of the specimens in $3.5 \% \mathrm{NaCl}$ solution.

The morphologies of the specimens after different immersion time are shown in Figure 2. It can be seen that when the specimens are immersed in $\mathrm{NaCl}$ solution, the surface forms black pits, which demonstrated that the pitting corrosion happens on the surface for $1 \mathrm{~h}$. As the immersion time increases to $3 \mathrm{~h}$, the surface is impregnated and the pits become dense, some of which develop to line. As the reaction continues, a big gray-green corrosion hole forms and gradually evolves into severe corrosion (6-12 h). The corrosion expands from the corrosion holes, which accelerates the corrosion, until the corrosion products almost cover the whole specimen surface $(24 \mathrm{~h})$.

In order to further study the evolution of the corrosion in $\mathrm{NaCl}$ solution, the micro morphologies after immersion for different time were characterized by SEM, which are shown in 

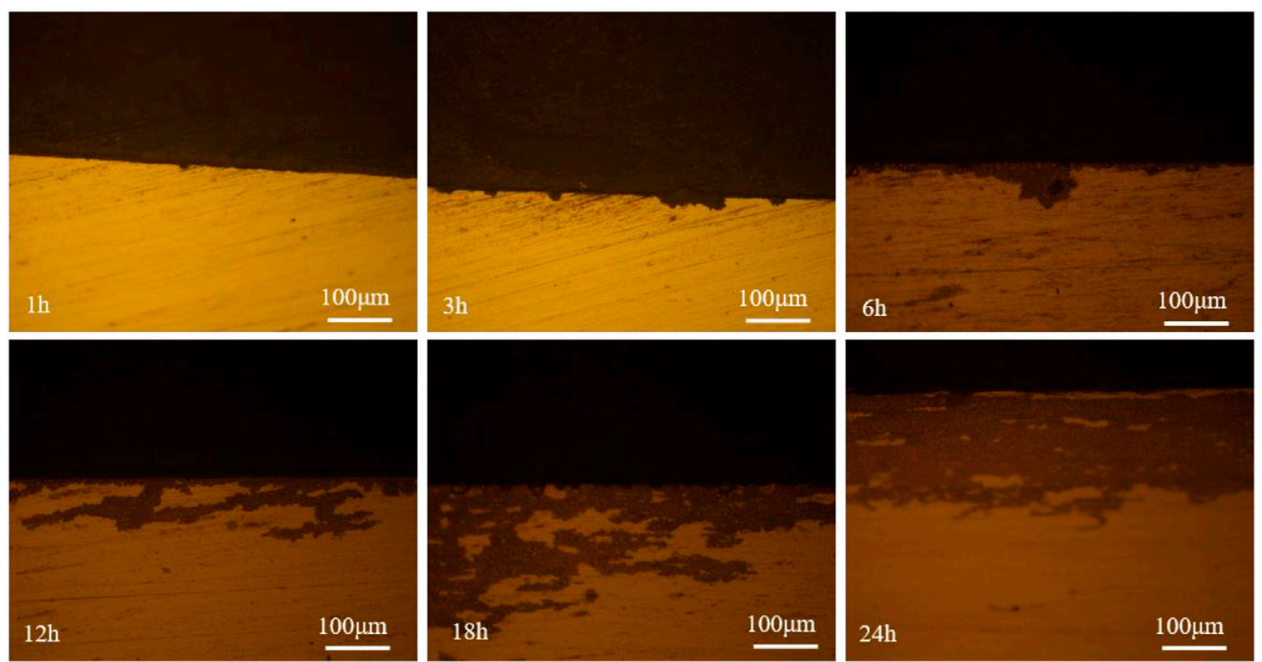

FIGURE 4 | Cross-section morphologies of the specimens in $3.5 \% \mathrm{NaCl}$ solution.

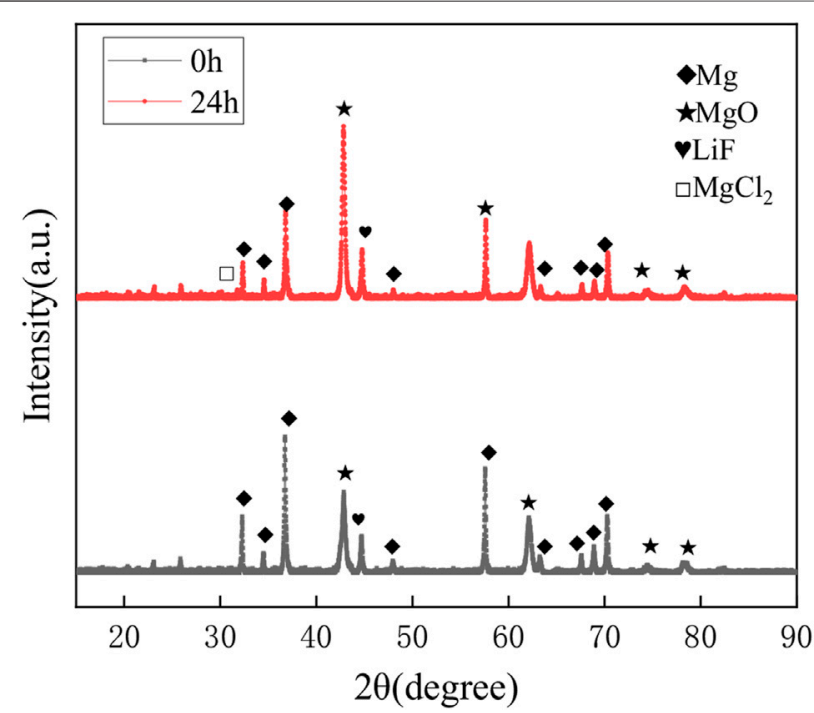

FIGURE 5 | XRD results of the specimens in $3.5 \% \mathrm{NaCl}$ solution.

Figure 3. After oxidation, the surface film is flat and locally covered with micro cracks. When immersed in the $\mathrm{NaCl}$ solution for $1 \mathrm{~h}$, the electro active surface of the sample is dissolved and the corrosion products fall off, which promotes to the formation of pits. As the corrosion develops, the corrosion pit expands along the grain boundary $(12 \mathrm{~h})$ and the corrosion products present river-like morphology $(12-18 \mathrm{~h})$. As the corrosion exacerbates, fluffy corrosion products cover the surface of the sample.

The cross-section morphologies were characterized and shown in Figure 4. It can be seen that in the early stage of immersion $(1 \mathrm{~h})$, the corrosion is slight, and sporadic corrosion pits exist on the surface. Once the pit forms, the pits develop rapidly, which connect to form notch

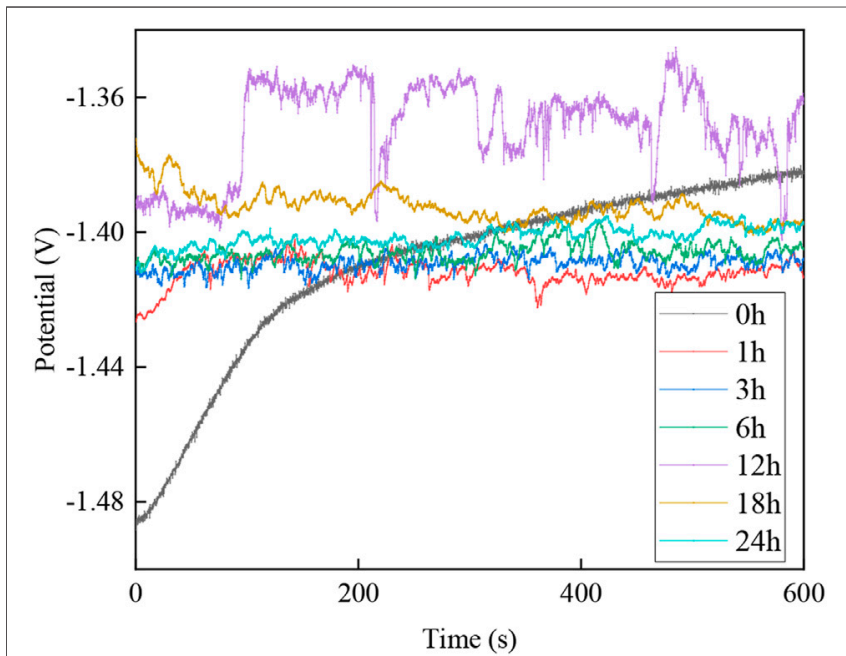

FIGURE 6 | Open circuit potential (OCP) plots of specimens with different immersion time.

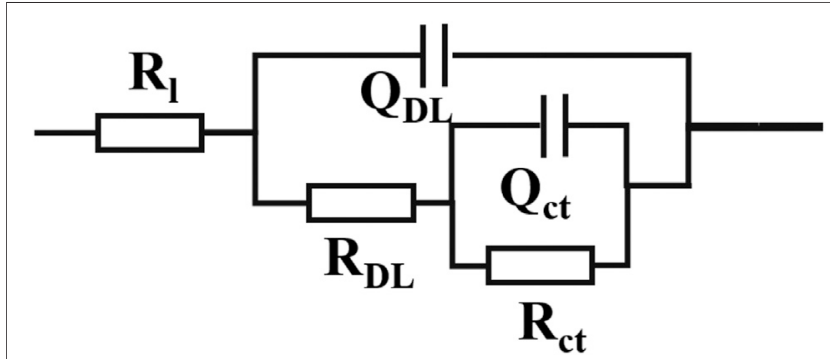

FIGURE 7 | Electrical equivalent circuit model for the EIS results, $R(Q)(R$ $(Q R)))\left(R_{l}\right.$ stands for solution resistance, $Q_{D L}$ and $R_{D L}$ are electric double layer capacitance and resistance respectively, $Q_{c t}$ and $R_{c t}$ are reaction capacitance and resistance respectively; $Q$ is a constant phase angle element). 

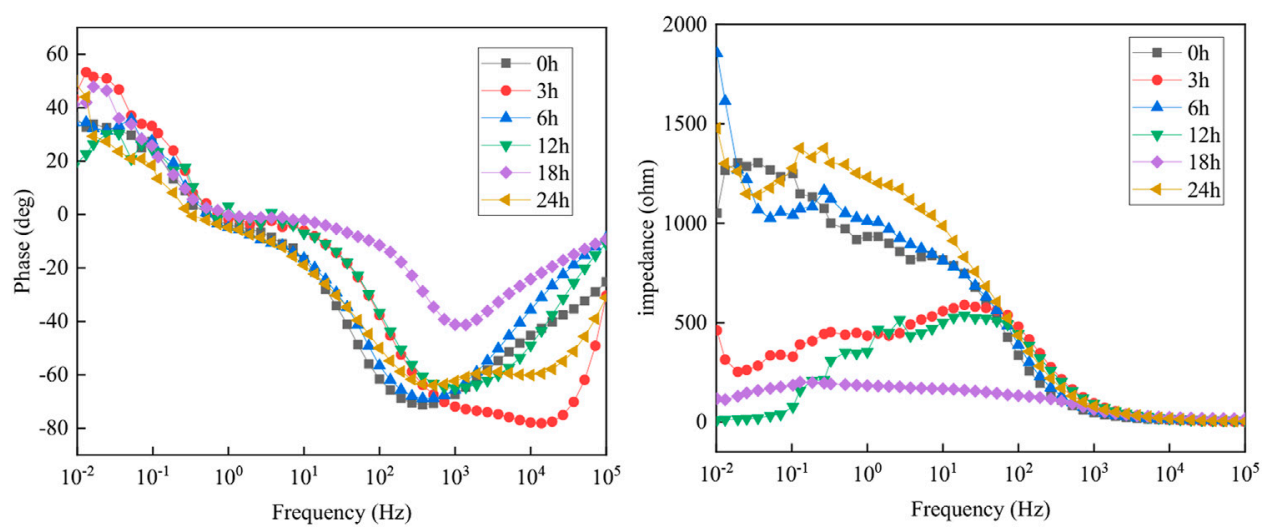

FIGURE 8 | EIS results of specimens after different immersion time.

TABLE 2 | Fitted data by Zsimpwin of EIS results.

\begin{tabular}{|c|c|c|c|c|c|c|c|}
\hline \multirow[t]{2}{*}{ Time (h) } & \multirow[t]{2}{*}{$\mathbf{R}_{\mathrm{l}}$ (ohm) } & \multicolumn{2}{|c|}{$\mathbf{Q}_{\mathrm{DL}}$} & \multirow[t]{2}{*}{$\mathbf{R}_{\mathrm{DL}}$} & \multicolumn{2}{|c|}{$\mathbf{Q}_{\mathrm{ct}}$} & \multirow[t]{2}{*}{$\mathbf{R}_{\mathrm{ct}}$ (ohm) } \\
\hline & & $Y_{\mathrm{DL}}\left(\Omega^{-1} \mathrm{~cm}^{-2} \mathrm{~s}^{-\mathrm{n}}\right)$ & $\mathbf{n}$ & & $Y_{\mathrm{DL}}\left(\Omega^{-1} \mathrm{~cm}^{-2} \mathrm{~s}^{-\mathrm{n}}\right)$ & $\mathbf{n}$ & \\
\hline 0 & 13.02 & $4.129 \times 10^{-6}$ & 0.8907 & 947.8 & $7.660 \times 10^{-6}$ & 0.9453 & $1,050.5$ \\
\hline 3 & 10.72 & $6.858 \times 10^{-6}$ & 0.9324 & 664.1 & $4.393 \times 10^{-6}$ & 1 & 497.2 \\
\hline 6 & 8.95 & $8.897 \times 10^{-6}$ & 0.9645 & 411.1 & $9.972 \times 10^{-7}$ & 1 & 475.7 \\
\hline 12 & 15.91 & $2.608 \times 10^{-6}$ & 0.7756 & 334.1 & $7.106 \times 10^{-7}$ & 1 & 65.8 \\
\hline 18 & 17.85 & $1.783 \times 10^{-6}$ & 0.7403 & 186.5 & $5.322 \times 10^{-7}$ & 1 & 103.6 \\
\hline 24 & 22.37 & $1.282 \times 10^{-6}$ & 0.7193 & 122.6 & $2.628 \times 10^{-7}$ & 1 & $1,301.4$ \\
\hline
\end{tabular}

morphology. And the corrosion expands to depth direction, promoting the formation of corrosion holes. Based on the corrosion pits, the horizontal expansion of corrosion is obviously better than the vertical expansion, and finally a piece of corrosion morphology is formed, which gradually covers the entire sample surface.

The corrosion products were analyzed by XRD and the results are shown in Figure 5. It can be found that the oxidation film is consisted with $\mathrm{MgO}, \mathrm{LiF}$, and $\mathrm{MgCl}_{2}$. As the corrosion happens, the diffraction peak intensity of $\mathrm{MgO}$ is much higher than that of $\mathrm{Mg}$, which shows the opposite characters for $0 \mathrm{~h}$, and the corrosion products contains $\mathrm{MgCl}_{2}$, which indicates that Chloride ions participate in the reaction and promote the formation of corrosion products.

\section{Electrochemical Results}

The OCP results of the specimens after different immersion time are shown in Figure 6. After immersion, the potential of the sample quickly becomes positive and gradually stabilizes. With the immersion time increase, the open circuit potential becomes positive until $12 \mathrm{~h}$ and then gradually negative. It indicated that at the early stage (before $12 \mathrm{~h}$ ), the corrosion product attaches to the surface and prevents the corrosion from developing, but as the immersion time goes on, the corrosion products become loose and blade off from the surface.

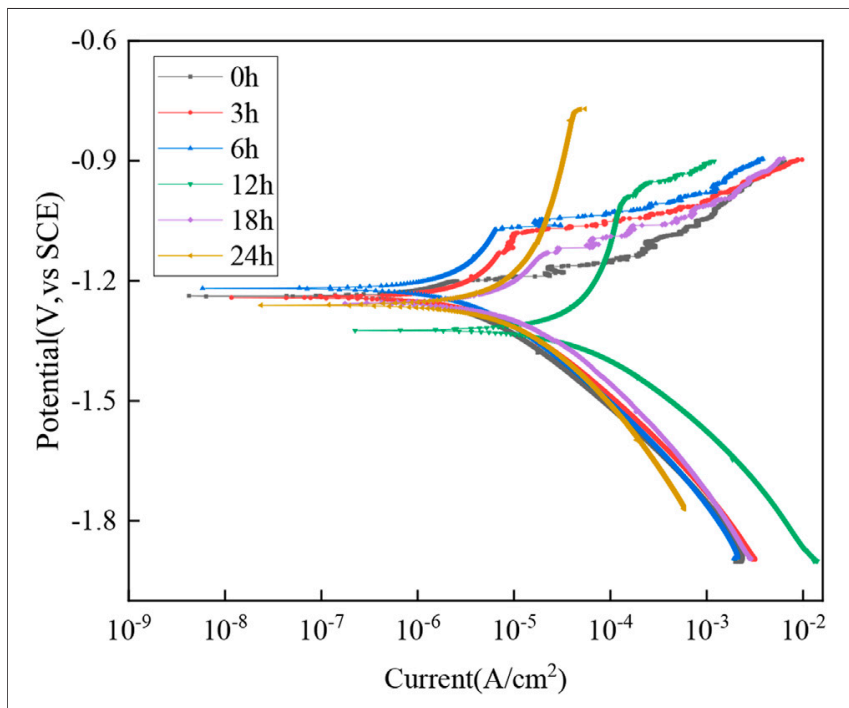

FIGURE 9 | The polarization curves of the specimens with different immersion time.

The structure of the electrochemical model of the specimens was characterized by EIS, and the fitting results for different immersion time of all specimens according to the electrical 
TABLE 3 | The fitting calculation results for linear polarization zone of polarization curves.

\begin{tabular}{lcccc} 
Time (h) & $\mathbf{E}_{\text {corr }}(\mathbf{V})$ & $\mathbf{I}_{\mathbf{c o r r}}\left(\mathbf{A} / \mathbf{c m}^{\mathbf{2}}\right)$ & $\mathbf{b}_{\mathbf{a}}\left(\mathbf{m V ~} \mathbf{d e c}^{-\mathbf{1}}\right)$ & $\mathbf{b}_{\mathbf{c}}\left(\mathbf{m V ~ d e c} \mathbf{~ d e}^{\mathbf{1}}\right)$ \\
\hline 0 & -1.255 & $2.435 \times 10^{-6}$ & 168.9 & -132.1 \\
3 & -1.250 & $8.747 \times 10^{-6}$ & 67.5 & -125.7 \\
6 & -1.232 & $9.238 \times 10^{-6}$ & 67.2 & -124.5 \\
12 & -1.318 & $5.861 \times 10^{-4}$ & 38.6 & -113.2 \\
18 & -1.247 & $1.103 \times 10^{-5}$ & 69.2 & -111.7 \\
24 & -1.286 & $1.165 \times 10^{-5}$ & 75.3 & -110.3
\end{tabular}

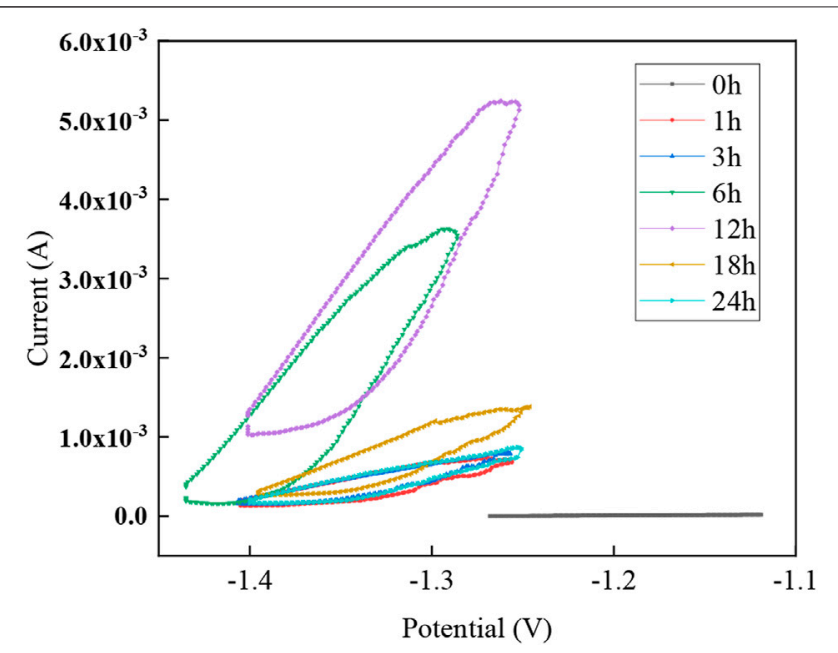

FIGURE 10 | The cyclic voltammetry curves after different immersion time.

equivalent circuit model in Figure 7 are shown in Figure 8 and Table 2, respectively. From the $\mathrm{Q}_{\mathrm{ct}}$ results can be seen that the capacitance value decreases from $7.660 \times 10^{-6} \Omega^{-1} \mathrm{~cm}^{-2} \mathrm{~s}^{-\mathrm{n}}$ to
$7.660 \times 10^{-6} \Omega^{-1} \mathrm{~cm}^{-2} \mathrm{~s}^{-\mathrm{n}}$ as the immersion time increases from 0 to $24 \mathrm{~h}$, which demonstrated that the resistance of corrosion product layer is reduced. However, although the reaction resistance is lower than that without immersion, as the immersion time increases from $1 \mathrm{~h}$ to $12 \mathrm{~h}$, the reaction resistance decreases from $1,050.5 \Omega$ to $65.8 \Omega$, indicating that the corrosion resistance of the sample decreases. From 12 to $24 \mathrm{~h}$, the reaction resistance increases from 65.8 to $1,301.4 \Omega$. Combined with the morphologies, the corrosion happens when the specimens immersing in the $\mathrm{NaCl}$ solution and mainly forms pits and holes before $12 \mathrm{~h}$, and then the corrosion products formed on the surface for $12-24 \mathrm{~h}$, which has a certain blocking effect in the film layer, and the corrosion rate decreases.

The polarization plots after different immersion time are shown in Figure 9. The self-corrosion potential and selfcorrosion current obtained by the linear fitting for polarization zone are given in Table 3. Compared with the non-immersed sample, the immersed sample has a smaller corrosion current and higher corrosion resistance, which indicates that the immersion reduced the corrosion resistance of the film. The self-corrosion potential shows the same trend with the open circuit potential. From the self-corrosion, current data show that the current increases from $2.435 \times 10^{-6} \mathrm{~A} / \mathrm{cm}^{2}$ to $5.861 \times 10^{-4} \mathrm{~A} / \mathrm{cm}^{2}$ before $12 \mathrm{~h}$, which indicates that the corrosion reaction is exacerbated, consistent with the reaction resistance. However, as the corrosion products cover the reaction area (anodic zone), which prevents the corrosion, the anodic resistance $\left(b_{a}\right)$ of the specimen increases after $12 \mathrm{~h}$. However, the cathode area is still exposed to the solution and the continuous reaction leads to a decrease in cathode reaction resistance $\left(b_{c}\right)$ from

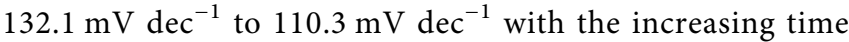
from 0 to $24 \mathrm{~h}$.

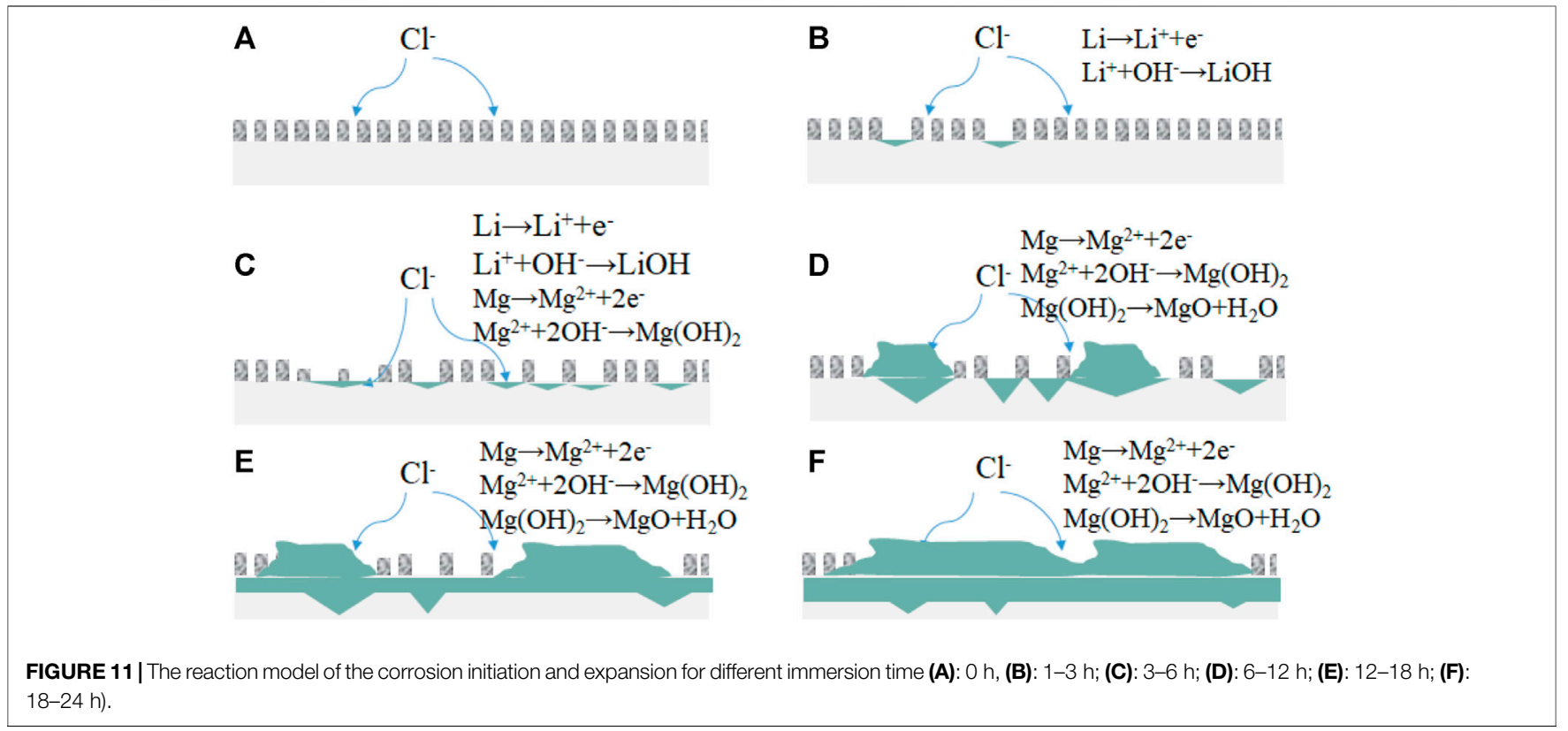


The cyclic voltammetry curves after different immersion time are shown in Figure 10. It can be seen that the current response to voltage change of the specimens without immersion is the smallest and basically presents a reversible process, which indicates that the sample has good corrosion resistance. The corrosion processes are shown in Figure 11. As the reaction time increases from 0 to $12 \mathrm{~h}$, the current response is more obvious and the degree of reversibility gets lower and lower, which demonstrates that the electrochemical reaction is more and more violent. But the irreversible process of the reaction weakens from 12 to $24 \mathrm{~h}$, which is caused by the corrosion products.

\section{Discussion}

From the corrosion morphologies, composition of the corrosion products, and the electrochemical results, the process of corrosion initiation and development is given as Figure 10. The corrosion process can be concluded into the following processes.

The initial stage of corrosion initiation (a-b) is mainly the formation of pits due to the electrochemical solution of $\mathrm{Li}$, as it is the most electrochemically active element. When the immersion continues, the element $\mathrm{Mg}$ happens in corrosion, and Li reacts further and dissolves off, which leads to the pits expanding to corrosion holes (b-c), and corrosion rate increasing as the corrosion products accumulate on the surface of the specimen (c-d), the micro-electro-battery and dissolution effect are more obvious, and the corrosion is further intensified, and corrosion develops mainly towards horizontal (d-e). However, after the corrosion products cover most of the surface, the micro-battery effect reduces, and the horizontal reaction slows down. And the corrosion products on the surface changes from $\mathrm{Mg}(\mathrm{OH})_{2}$ to $\mathrm{MgO}$, which is more loose than $\mathrm{Mg}(\mathrm{OH})_{2}$, leading to depth corrosion acceleration.

\section{REFERENCES}

Chen, D. C., Wu, J. F., Liang, Y. Q., Ye, S. L., and Li, W. F. (2011). Preparation and Elements Analysis of Porous Fluorescent Glasses. Trans. Nonferrous Met. Soc. China. 21, 1905-1910. doi:10.1016/s1003-6326(11)60948-5

Fernández, J., El Ouardi, Y., Bonastre, J., Molina, J. M., and Cases, F. (2019). Modification of the Magnesium Corrosion Rate in Physiological saline $0.9 \mathrm{Wt} \%$ $\mathrm{NaCl}$ via Chemical and Electrochemical Coating of Reduced Graphene Oxide. Corros. Sci. 152, 75-81. doi:10.1016/j.corsci.2019.01.025

Formosa, J., Chimenos, J. M., Lacasta, A. M., and Niubo, M. (2012). Interaction between Low-Grade Magnesium Oxide and Boric Acid in Chemically Bonded Phosphate Ceramics Formulation. Ceram. Int. 38, 2483-2493. doi:10.1016/ j.ceramint.2011.11.017

Guo, L., Zhang, F., Song, L., Zeng, R.-C., Li, S.-Q., and Han, E.-H. (2017). Corrosion Resistance of Ceria/polymethyltrimethoxysilane Modified Magnesium Hydroxide Coating on AZ31 Magnesium alloy. Surf. Coat. Tech. 328, 121-133. doi:10.1016/j.surfcoat.2017.08.039

Liu, R., Liu, Z. H., Wang, F., Jia, Y. F., Ding, Y. D., Ban, G. D., et al. (2016). Development of Corrosion Surface Modification Technology for Magnesium Alloys. Mater. Protect. 45 (4), 124-133. doi:10.16490/j.cnki.issn.10013660.2016.04.021

Liu, S., Qi, Y., Peng, Z., and Liang, J. (2021). A Chemical-free Sealing Method for Micro-arc Oxidation Coatings on AZ31 Mg alloy. Surf. Coat. Tech. 406, 126655-126665. doi:10.1016/j.surfcoat.2020.126655
The wedge effect of corrosion products leads to thickening of corrosion products.

\section{CONCLUSION}

1) The corrosion of Mg-Li alloy with chemical oxidation film starts from pitting corrosion, gradually expands in depth in the early stage, forms corrosion holes, and then gradually develops into river-like morphology. In the last stage, the increasing corrosion products slow down the corrosion rate and gradually cover the entire sample surface.

2) The corrosion product is mainly consisted with $\mathrm{MgO}, \mathrm{LiF}$, and $\mathrm{MgCl}_{2}$.

3) The initial stage of corrosion initiation is mainly the formation of pits due to the electrochemical solution of Li. When the immersion continues, the element $\mathrm{Mg}$ happens as corrosion, and $\mathrm{Li}$ reacts further and dissolves off, leading to the pits expanding to corrosion holes. As the corrosion products accumulate on the surface of the specimen, the microelectro-battery and dissolution effect are more obvious, and the corrosion is further intensified, and corrosion develops mainly towards horizontal.

\section{DATA AVAILABILITY STATEMENT}

The raw data supporting the conclusions of this article will be made available by the authors, without undue reservation.

\section{AUTHOR CONTRIBUTIONS}

All authors listed have made a substantial, direct, and intellectual contribution to the work and approved it for publication.

Prando, D., Nicolis, D., Bolzoni, F., Pedeferri, M., and Ormellese, M. (2019). Chemical Oxidation as Repairing Technique to Restore Corrosion Resistance on Damaged Anodized Titanium. Surf. Coat. Tech. 364, 225-230. doi:10.1016/ j.surfcoat.2019.03.005

Qiu, Z.-m., Zeng, R.-c., Zhang, F., Song, L., and Li, S.-q. (2020). Corrosion Resistance of $\mathrm{Mg}-\mathrm{Al} \mathrm{LDH} / \mathrm{Mg}(\mathrm{OH}) 2 /$ silane-Ce Hybrid Coating on Magnesium alloy AZ31. Trans. Nonferrous Met. Soc. China 30, 2967-2979. doi:10.1016/s1003-6326(20)65435-8

Shao, Z., Zhang, F., and Zhang, Q. (2017). Preparation of Grayish Black Film on Am50 Magnesium Alloy by Chemical Conversion-Micro-Arc Oxidation. Surf. Rev. Lett. 24 (1), 1750012-1750019. doi:10.1142/s0218625x17500123

Shi, P., Niu, B., and Li, Q. (2015). Preparation and Characterization of PLA Coating and PLA/MAO Composite Coatings on AZ31 Magnesium alloy for Improvement of Corrosion Resistance. Surf. Coat. Tech. 262, 26-32. doi:10.1016/j.surfcoat.2014.11.069

Sun, Y., Wang, R., Peng, C., and Cai, Z. (2020). Microstructure and Corrosion Behavior of As-Extruded Mg-xLi-3Al-2Zn-0.2Zr Alloys (X = 5, 8, 11 wt.\%). Corrosion Sci. 167, 108487-108501. doi:10.1016/j.corsci.2020.108487

Wang, W., Qiao, X. L., Chen, J. G., and Li, H. J. (2007). Facile Synthesis of Magnesium Oxide Nanoplates via Chemical Precipitation. Mater. Lett. 61, 3218-3220. doi:10.1016/j.matlet.2006.11.071

Wu, G., Zhao, D., Lin, X., Liu, J., and Ji, X. (2020). Investigation of an Environmentally Friendly Coloring Coating for Magnesium-Lithium alloy Micro-arc Oxidation. Surf. Inter. 20, 100513-100518. doi:10.1016/ j.surfin.2020.100513 
Wu, G., Zhao, D., and Sun, L. (2020). Microstructure and Mechanical Properties of Wire-Filled Tungsten Argon Arc Welded Joints for LA141 MagnesiumLithium-Aluminum alloy. Mater. Today Commun. 23, 100881-100886. doi:10.1016/j.mtcomm.2019.100881

Xia, Q., Zhang, D., Li, D., Jiang, Z., and Yao, Z. (2019). Preparation of the Plasma Electrolytic Oxidation Coating on $\mathrm{Mg} \mathrm{Li}$ alloy and its thermal Control Performance. Surf. Coat. Tech. 369, 252-256. doi:10.1016/ j.surfcoat.2019.04.073

Xu, H., Wang, Q., and Zhang, Z. (2008). Mater. Prot. 41 (9), 20-23.

Yang, W., Xu, D., Wang, J., Yao, X., and Chen, J. (2018). Microstructure and Corrosion Resistance of Micro Arc Oxidation Plus Electrostatic Powder Spraying Composite Coating on Magnesium alloy. Corrosion Sci. 136, 174-179. doi:10.1016/j.corsci.2018.03.004

Zhang, Y., Chen, F., Zhang, Y., Liu, Z., Wang, X., and Du, C. (2019). Influence of Graphene Oxide on the Antiwear and Antifriction Performance of MAO Coating Fabricated on Mg Li alloy. Surf. Coat. Tech. 364, 144-156. doi:10.1016/j.surfcoat.2019.01.103
Conflict of Interest: The authors declare that the research was conducted in the absence of any commercial or financial relationships that could be construed as a potential conflict of interest.

Publisher's Note: All claims expressed in this article are solely those of the authors and do not necessarily represent those of their affiliated organizations, or those of the publisher, the editors, and the reviewers. Any product that may be evaluated in this article, or claim that may be made by its manufacturer, is not guaranteed or endorsed by the publisher.

Copyright (c) 2021 Wen, Bai, Zhao, Cui, Jiao, Wang and Zhang. This is an openaccess article distributed under the terms of the Creative Commons Attribution License (CC BY). The use, distribution or reproduction in other forums is permitted, provided the original author(s) and the copyright owner(s) are credited and that the original publication in this journal is cited, in accordance with accepted academic practice. No use, distribution or reproduction is permitted which does not comply with these terms. 